Article

\title{
Rainwater Harvesting and Social Networks: Visualising Interactions for Niche Governance, Resilience and Sustainability
}

\author{
Sarah Ward * and David Butler \\ Centre for Water Systems, College of Engineering, Mathematics and Physical Sciences, University of Exeter, \\ North Park Road, Exeter EX4 4QF, UK; d.butler@exeter.ac.uk \\ * Correspondence: sarah.ward@exeter.ac.uk \\ Academic Editor: Manfred Kleidorfer \\ Received: 2 August 2016; Accepted: 7 November 2016; Published: 11 November 2016
}

\begin{abstract}
Visualising interactions across urban water systems to explore transition and change processes requires the development of methods and models at different scales. This paper contributes a model representing the network interactions of rainwater harvesting (RWH) infrastructure innovators and other organisations in the UK RWH niche to identify how resilience and sustainability feature within niche governance in practice. The RWH network interaction model was constructed using a modified participatory social network analysis (SNA). The SNA was further analysed through the application of a two-part analytical framework based on niche management and the safe, resilient and sustainable ('Safe and SuRe') framework. Weak interactions between some RWH infrastructure innovators and other organisations highlighted reliance on a limited number of persuaders to influence the regime and landscape, which were underrepresented. Features from niche creation and management were exhibited by the RWH network interaction model, though some observed characteristics were not represented. Additional Safe and SuRe features were identified covering diverse innovation, responsivity, no protection, unconverged expectations, primary influencers, polycentric or adaptive governance and multiple learning-types. These features enable RWH infrastructure innovators and other organisations to reflect on improving resilience and sustainability, though further research in other sectors would be useful to verify and validate observation of the seven features.
\end{abstract}

Keywords: infrastructure; integrated model; niche; organisation; rainwater harvesting; resilience; social network analysis; sustainability

\section{Introduction}

Against a backdrop of climate change, population growth and urbanisation, scholars past and present have and are examining the ways in which complex systems cope, or change and adapt to survive [1,2]. The way in which water is provided and used can be regarded as a complex system, due to the interlinked and interactive nature of social, ecological and technical systems [3]. In order to become more sustainable and resilient, a range of scholars argue that the water 'system' must undergo a transition or paradigm shift or that radical change must be able to occur within the existing regime [4-6].

In order to successfully model these transitions and shifts, a more integrated consideration of water supply and drainage systems, as well as social, ecological and technical systems is required; segmentation fails to recognise interactions and complexities [7]. To model components of the water sector, coupled models of natural and human water infrastructures have emerged [8-10], as have models to integrate urban growth and water infrastructure [11,12] and to assess the relative merits of green versus grey infrastructures [13]. High-level socio-technical models that aim to better 
represent decentralised and alternative water supply systems (AWSS) and decision-making in the water infrastructure selection and transition process have also been forthcoming [2,14-16].

However, the high-level nature of these models can result in poor representation of the complexities between infrastructure (technologies) and organisations (social networks) across the multiple levels operating within a sector. Using influences from transition studies, specifically the multi-level perspective (MLP) [17] and technological innovation systems (TIS) [18], the authors define and summarise the relationship between the different levels operating in the water MLP in Figure 1. The MLP comprises the landscape, regime and niche and represents interactions between individuals, organisations, sectors and societies, asserting that on the journey of increasing sustainability and resilience in the water sector the regime and landscape change in response to niche innovations, usually in relation to a crisis (for example, climate change or population growth).

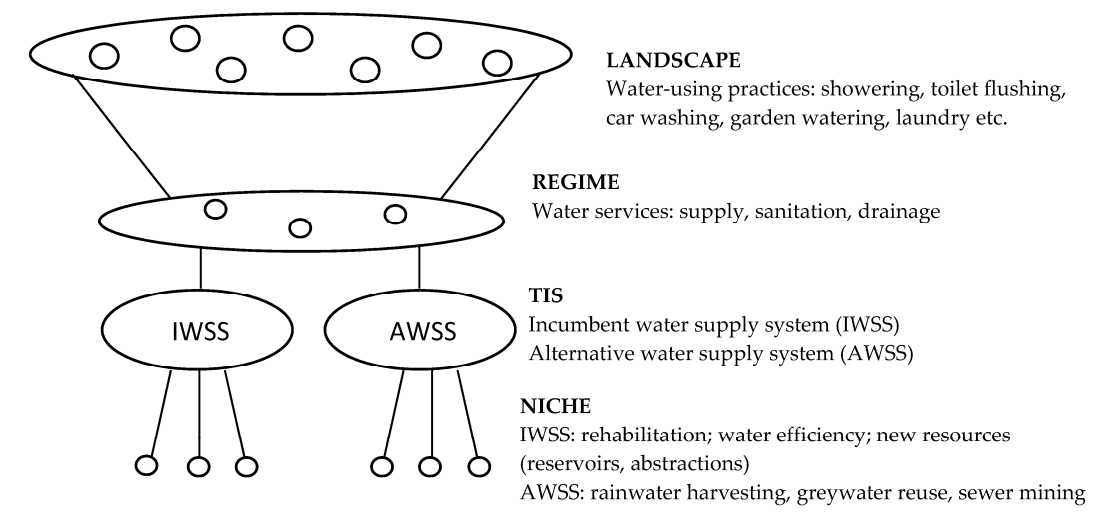

Figure 1. The multi-level perspective (landscape, regime, niche) and corresponding technological innovation systems (TIS) for the water sector.

Within the MLP, socio-technical niches (in this case incumbent or alternative techniques such as water efficiency or rainwater harvesting $(\mathrm{RWH})$, respectively) represent innovative bottom-up experiments that challenge incumbent regime-level practices (in this case not using water efficiently or using potable water for non-potable end-uses). Where such challenges are successful and practices change, steps are achieved towards a transition or shift [19,20]. This is perhaps evident in the case of water efficiency where the majority of water-saving practices (e.g., showering instead of taking a bath) are becoming social norms (in the UK at least), even if approaches to behaviour change are contested [21]. Recent research has focused on the niche level, including advancing the understanding of firm/company-level contributions to sustainability transitions and suggesting approaches to strategic, conceptual and social niche management [22-25]. Additionally, recent research on niche interactions using agent-based models showed that infrastructure-organisation interactions were critical for niche formation, technology adoption and transitions relating to infrastructure [26].

In parallel to the development of a range of niche management approaches and to reflect on the outcomes of niche experimentation, the concept of open and dynamic societal networks of innovation or 'transition arenas' (TAs) emerged to facilitate interaction, knowledge exchange and learning [27,28]. Comprised of a small network of frontrunners (around a dozen individuals, not organisations), TAs represent a range of backgrounds and interpretations of particular transition issues. Frontrunners may be non-experts or opinion leaders, but should represent a range of organisational levels from the public, private and third sectors, as well as intermediaries. In considering each experiment taking place within a niche, the frontrunners aim to reach a consensus on the problem, develop a vision and then move forward on a transition path $[29,30]$.

However, there has been criticism of this approach as being technocratic, with doubt placed on the abilities of niches and TAs to fully lead, vision and drive change in regimes from the bottom-up, where the issue may really be that of broader reflexive governance in political and economic circles $[31,32]$. 
Also using the MLP, Nastar [32] highlights interactions between actors in the water regime and niche experiments relating to rainwater harvesting (RWH) in Hyderabad, demonstrating the need for socio-technical and socio-political innovations to be combined. Integration of infrastructures and organisations in this way, would enable a new vision to replace the old (in that case representing a regime imposed by international aid). Whilst using the MLP, the analysis follows a narrative analytical framework, limiting visualisation of the interactions described and analysed. Wen et al. [33], in their work on international, interdisciplinary and intersectoral modelling for urban water management, further develop the case for the use of quantitative social science modelling techniques such as social network analysis (SNA), initiated by Binz and Truffer [18]. Conventional SNA has been utilised to examine social networks in economic geography [34], innovation studies and energy sector innovation [35], renewable energy supplies such as biofuels [36] and for the water management sector, membrane bioreactors at a global scale [18]. However, SNA has yet to be applied at the national niche scale for water infrastructure, such as AWSS or RWH. Modelling and visualisation of niche-level infrastructure and organisation interactions could be a useful approach to improve visioning and transitioning in a sector that has been criticised for lacking innovation in a world of global challenges where the innovation agenda is key [37]. As the regime and landscape change in response to niche innovations and RWH is a niche innovation, it is therefore fundamental to examine how the network representing the niche operates and is governed in order to ascertain the directionality of influences to and from the regime and landscape. Social network analysis thus comprises a valuable, but challenging, research method to examine the RWH network.

In addition to the innovation agenda and the well-established sustainability agenda, a recent agenda to emerge in the water sector (following its embedding in other sectors and fields), is that of the resilience agenda. A range of organisations have acknowledged the significance of water resource, supply and sanitation resilience in the face of challenges or threats (such as climate change, population growth and urbanisation) and advocated developing long-term resilience through strengthening infrastructure and organisations [38-40]. As with most concepts, contestation over definitions and operationalisation of resilience exists, as does debate over suitable indicators and metrics through which to measure resilience, particularly within the water sector [4]. Continuation of that debate is beyond the scope of this paper, instead this paper focuses on the definitions of resilience and sustainability advocated in Butler et al. $[4,41]$ as part of the reliable, resilient and sustainable framework —or 'Safe and SuRe' framework for short (safe taken as representing reliable and SuRe representing sustainable and resilient, respectively).

Within the Safe and SuRe framework, resilience is defined as:

"the degree to which the system minimises level of service failure magnitude and duration over its design life when subject to exceptional conditions".

Essentially, this is a measure of system performance in relation to threats that place stresses on a system (social, ecological, technical or otherwise) causing it to strain. In this way, the definition echoes references to bounce-back-ability, rapid recovery and adaptation in relation to failures inherent in many other resilience definitions [42].

Sustainability is taken as being:

"the degree to which the system maintains levels of service in the long-term whilst maximising social, economic and environmental goals".

Again, this reflects the conventional three pillars of sustainability that are to be maintained or enhanced for future generations. To apply these definitions, the Safe and SuRe framework supports four types of evaluation (top-down, bottom-up, middle-based and circular) across modules representing threats, systems, impacts (on system performance) and consequences (for society, economy and environment). By identifying multiple opportunities for intervention between these modules, mitigation, adaptation, coping and learning for reliability, resilience and sustainability can 
be undertaken. In earlier work, the framework was applied to primarily incumbent urban water infrastructures such as wastewater treatment works and urban drainage systems [43,44].

This paper presents a UK-based pilot study into the use of a modified participatory SNA method to model and visualise the interactions between RWH infrastructure innovators (technologies) and other organisations to examine how resilience and sustainability feature within niche and TA processes. First, a social network model representing RWH infrastructure innovator and organisation interactions is constructed. Second, SNA is undertaken using appropriate metrics to visualise and interrogate interactions. Third, an analytical framework comprised of MLP niche management perspectives and the Safe and SuRe approach is utilised to identify features of innovation, resilience and sustainability within modelled RWH infrastructure-organisation interactions. A final discussion and conclusion section triangulates and recontextualises the outcomes of the study, providing decision and policy makers with reflective insights on implications for the future of the RWH sector.

\section{Methodology}

The methodology for the pilot study comprised three parts. First, the construction of a social network model representing the infrastructures and organisations operating in the UK RWH niche and TA was undertaken using a modified participatory approach. Second, the application of SNA using a proprietary software tool. Third, the application of an analytical framework consisting of niche management elements of the MLP and definitions of resilience and sustainability from the Safe and SuRe framework. The first two parts are described together in the next section and the third part is described in the subsequent section.

\subsection{Social Network Construction and Analysis}

Social networks map the relationships between actors and consideration of such maps gave rise to the development and application of SNA, emphasizing the importance of patterns of interaction [45]. The primary focus of SNA is relational data and its analysis, based on the construction of a social network. SNA enables investigators to look beyond individuals' attributes to reflect on overall network patterns (actor positions, relations and structures) and thus the inclusion of formal and informal actors can be crucial [46]. A limitation of its conventional utilisation is the requirement for matrices of bibliometric or citation data that catalogue the interactions between different entities. SNA tools are then used to evaluate different network properties such as centrality, connectivity, and clusterability, each of which pertain to particular dimensions of the network [47]. The bibliometric approach used by [18] would not easily translate to other contexts where a number of actors or actor categories (for example a wide range of organisations) may be located outside of the formal publications sphere. Additionally, the lag time between action in practice and eventual publication means that the dynamic real-time development of a network, niche or TA could be overlooked.

An alternative to the bibliometric approach is that of participatory SNA (PSNA), which is gaining popularity in research areas where quantitative data matrices may be less easily obtainable [47]. PSNA engages actors (who may represent organisations) in workshops to co-create a representation of a network (for example by drawing symbols or writing names on paper and then connecting them using lines) and has been widely used in relation to health service issues and natural resource utilisation and management $[46,48-51]$. PSNA can increase the understanding of a social network beyond that of purely structure-driven aspects, to include relationships between incumbent actors (in the case presented here, water infrastructure providers such as water companies) and new entrants (in this case of RWH infrastructure innovators), as well as the plethora of other organisations that may constitute a network. Despite its emergence as a sophisticated tool for modelling cross-system interactions and its advantages over conventional SNA, PSNA presents some major disadvantages. One is the time and resources required to identify participants and undertake interviews or facilitate focus groups and workshops. Additionally, issues of power or influence and pre-existing conflicts between actors may threaten or bias participation in the process. 
Consequently, to construct a social network, the authors used a modified participatory approach to draw on the existing expertise and experience of individuals through the use of a reflexive autobiographical sketch. The focus of such an autobiographical sketch is the mapping and logging of a range of experiences, media and other evidence, which is in line with the methodology described and applied by Nastar [32] and comprising a personal triangulation of policy and document/media analysis, extracts from questionnaire and interview databases and intensive fieldwork. Triangulation of multiple sources of information or multiple representations of the interactions of a group of organisations is a standard approach in PSNA [52].

In the pilot study presented here, the lead author created an autobiographical sketch that triangulated roles and activities of relevance to $\mathrm{RWH}$, including research undertaken (questionnaires and interviews with RWH users and manufacturers, system testing), contacts made within the sector, membership of relevant organisations/networks (for example the UK Rainwater Management Association), professional interactions (RWH conferences, seminars, meetings and events) and publications completed (academic and grey). Readers are referred to Ward et al. [53] and Melville-Shreeve et al. [54] for a more detailed insight into the type of research, contacts and organisations engaged. However, it should be noted that whilst a range of organisations are referred to in these previous papers, they do not comprehensively address all of the organisations included in the present paper. This does not mean the organisations that are not included have received unequal treatment, rather that other observations and implicit knowledge generated from other interactions has been drawn upon to represent their position. Reflection on these experiences and interactions enabled the relationships between different RWH innovators operating in the niche and other individuals and groups undertaking activity on RWH to be identified. Mapping these relationships on paper snowballed the identification of other organisations and the representation of the social network expanded. Once the lead author had finished developing the representation of the RWH network, two colleagues with equal knowledge of and engagement with the RWH niche and water management sector thoroughly reviewed it to verify the information represented (to achieve a basic level of inter-rater reliability), by systematically checking each organisation and relationship included and commenting on any required revisions.

Whilst the colleagues agreed that the generated network adequately represented organisations operating in the UK RWH sector, it should be acknowledged it originates from their personal beliefs, experiences, understandings and subjective biases as participants within the RWH network and is time-specific i.e., based on information up to August 2014. This of course means the analysis does not capture, nor does it aspire to provide, a complete picture, but rather it seeks to be grounded on a specific and informed standpoint. As the compiler of the network is a researcher bound by academic and professional ethics, unlike the participants of a traditional PSNA, it could be argued that it is therefore more robust and separated from issues of power, influence and pre-existing conflicts. As Roex and Degryse [55] argued in other contexts, the recognition of personal interactions and narratives, self-analysis, reflection and action can enhance learning and considerably enriches traditional SNA approaches to understanding social networks. Consequently, the network generated articulates a specific viewpoint at a certain point in time, which may or may not represent the entire network under observation. The authors believe the method provides access to a source of data hitherto neglected in circles responsible for managing change in the water sector. Additionally, the work represents a pilot study, which could be expanded in further work by undertaking a more conventional PSNA with multiple participants in several workshops-including with those actors represented in the resulting social network.

The RWH innovators (taken in this analysis as representing RWH infrastructures/technologies) and other organisations dealing with RWH identified through the autobiographical sketch and network mapping exercise are summarised in Table 1. The relationships between these actors were used as a starting point to create a formalised model of the RWH social network. Visualising the relationships between the organisations through text has limitations. Consequently, a social network model (diagrammatic representation) was generated through which to analyse the identified relationships 
via SNA. Infrastructure components (nodes) of the model are represented by RWH infrastructure innovators, as these are responsible for designing, developing and manufacturing the actual physical RWH systems. All other nodes represent organisations that are either responsible for connecting RWH innovators to the incumbent regime, undertaking research on RWH or transferring knowledge on RWH through formal networks. Edges were added to represent relationships between the nodes (infrastructure and organisations). As well as the autobiographical sketch, the websites of the UK Rainwater Management Association and the Water Technology List (WTL) were used to contribute information in the development of the social network model, as they provide a list of their members. The Social Networks Visualizer, 'SocNetV' [56], cross-platform was used to generate the network model and perform analyses. Standard properties of the network model, such as density, diameter, connectedness and centralities [57], were then interrogated and are described in Section 3.1.

The RWH network model generated does not represent relationships between infrastructures or organisations in the wider water sector, a necessity in order to keep the boundaries of the analysis manageable during this pilot application. Furthermore, the focus was on RWH infrastructure innovators deemed to be innovative; that is actively developing new methods, products, processes, services or other provisions to enable the RWH sector to adapt and respond to the needs of markets, the regime and landscape (both RWH incumbents and new entrants are included). Finally, only organisations that are formal entities were included, that is, they are registered as a sole trader, company or similar.

A limitation of the generated network model is that it is not weighted. This would be where a weighting is placed on each of the relationships indicating the quality of the relationship, such as how often interactions occur, the nature of the interaction and so on. This information was not available in this case therefore it is not possible to consider the frequency or quality of interactions or interrogate factors such as how quickly information travels around the model. The information required to create a weighted network (meeting dates, durations, nature of discussions, outcomes etc.) could be gathered in future research, by integrating this analysis with a more extensive PSNA.

\subsection{Analytical Framework}

The visualisation and interrogation of RWH infrastructure-organisational interactions is enabled through the PSNA described in the previous section. However, to further extend the interrogation, it is important to recontextualise the quantitative SNA within a more qualitative narrative, particularly as niche management, innovation, resilience and sustainability agendas are of interest in this pilot study. Consequently, within this work, we have constructed an analytical framework comprised of aspects of the MLP and Safe and SuRe frameworks, that will be used to further analyse the RWH SNA.

There is a tendency in transition studies/MLP papers to reproduce and justify the fundamental aspects of the framework and there is criticism of and ongoing debate around the approach [31,32,58]. Whilst the scope of this paper does not allow such an extended account or direct addressing of this debate, it is important to identify and justify the use of the MLP in the pilot study. Firstly, as an analytical tool operating at multiple levels, it provides a useful set of concepts through which to categorise and understand system change processes at each of the levels. For example, niche management features include learning, networking, expectations, defining concepts, exploring social embedding, new partnership formation, experimentation, evaluation, identifying values, existence in the social economy, pluralism of resource base, presence of communities and enabling of conventional and alternative combinations. These features provide a frame through which to interrogate the interactions between infrastructure and organisations in the UK RWH SNA. Secondly, framing the results using niche management features from the MLP enables detailed discussion of social, technical and potentially political perspectives emerging within the RWH sector in the UK. This enables dissonance in perceptions, ambitions, visions and actions to be identified, elaborated and discussed in relation to their implications for the future of the sector. Whilst these features underpin the utility of the MLP in the present study, they also highlight gaps, specifically in relation to agendas beyond innovation and sustainability, most noticeably that of resilience. 
Table 1. Abbreviations, full names and brief descriptions of RWH infrastructure innovators and organisations identified through the modified participatory SNA that are included in the social network analysis.

\begin{tabular}{|c|c|c|c|}
\hline SNA No. & Abbreviation & Full Name & Description \\
\hline 1 & CWS & Centre for Water Systems & $\begin{array}{l}\text { World-leading research and teaching centre at the University of Exeter, RWH has been a research } \\
\text { stream since the 2000s }\end{array}$ \\
\hline 2 & UKRMA & $\begin{array}{l}\text { UK Rainwater Management } \\
\text { Assoc. }\end{array}$ & $\begin{array}{l}\text { Primarily a trade association with non-trade members, self-tasked lobbying group and } \\
\text { knowledge network }\end{array}$ \\
\hline 3 & WPT & Water Powered Technologies & $\begin{array}{l}\text { Cornish SME pioneering the application of RAM pumps in a variety of applications including RWH } \\
\text { ('Hydromentum') }\end{array}$ \\
\hline 4 & RainShare & RainShare & $\begin{array}{l}\text { The lead author's social enterprise, which aims to connect people with too much runoff with those } \\
\text { who need more via RWH }\end{array}$ \\
\hline 5 & 3PTechnik & 3PTechnik & $\begin{array}{l}\text { Self-badged 'rainwater people', operating for around } 30 \text { years, supplies components to the sector, } \\
\text { constantly looking for the next innovation }\end{array}$ \\
\hline 6 & FR & FlushRain & $\begin{array}{l}\text { Sole trader responsible for developing a novel retrofitable downpipe-mounted } \\
\text { low-volume/low-energy RWH system }\end{array}$ \\
\hline 7 & AA_KK & Aqua Analytics and Kloud Keeper & $\begin{array}{l}\text { SME designed the Kloud Keeper novel RWH system product. Tied to CWs via company director } \\
\text { being RWH EngD candidate }\end{array}$ \\
\hline 8 & StormS & Stormsaver & $\begin{array}{l}\text { Established in } 2003 \text { and 'UK market leader in the design and manufacture of RWH systems', internal } \\
\text { innovator and founder member of UKRMA. Responded to regulator pressure by launching a } \\
\text { new product }\end{array}$ \\
\hline 9 & Atlas & Atlas & SME selling and installing a novel retrofitable roof-mounted RWH system \\
\hline 10 & RainSafe & RainSafe & Irish SME developing and testing a novel treatment device for RWH systems \\
\hline 11 & $7 \mathrm{~T}$ & Severn Trent Water & $\begin{array}{l}\text { WSP at forefront of AWSS research/practice, setting up an national 'urban demonstrator' that will } \\
\text { include RWH }\end{array}$ \\
\hline 12 & UR & UrbanRain & European research consortium examining stormwater management across EU countries \\
\hline 13 & FreeR & FreeRain & $\begin{array}{l}\text { Founder member of the UKRMA, focused less on internal innovation, but always looking for the next } \\
\text { external innovation }\end{array}$ \\
\hline 14 & SWW & South West Water & $\begin{array}{l}\text { WSP with customers and the environment as its priority, currently trialling RWH as part of its } \\
\text { DownStream Thinking project }\end{array}$ \\
\hline 15 & RHS & RainHarvesting Systems & $\begin{array}{l}\text { Self-badged as the UK's 'original RWH company' (since 1997), a provider of RWH system components } \\
\text { and founder member of the UKRMA, more inclined to external innovation }\end{array}$ \\
\hline
\end{tabular}


Table 1. Cont

\begin{tabular}{|c|c|c|c|}
\hline SNA No. & Abbreviation & Full Name & Description \\
\hline 16 & Aquality & Aquality & $\begin{array}{l}\text { Well-established RWH supplier and installer, used to internally innovating in response to the market. } \\
\text { Launched a low-energy RWH system in response to regulatory pressures }\end{array}$ \\
\hline 17 & GrafUK & GrafUK & Well-established RWH supplier and installer, more of an external innovator \\
\hline 18 & AquaCo & AquaCo & $\begin{array}{l}\text { Designer and installer of RWH systems, also specialises in greywater systems, not particularly } \\
\text { active innovator }\end{array}$ \\
\hline 19 & HydroINT & HydroInternational & $\begin{array}{l}\text { Well-established RWH supplier and installer, used to internally innovating in response to the market, } \\
\text { at the forefront of the drainage sector }\end{array}$ \\
\hline 20 & ARUP & ARUP/PIPEX—Flowstow & $\begin{array}{l}\text { Consultancy and design, manufacture and installation of a range of plastic products, which designed a } \\
\text { novel RWH system, though one of its trial sites failed. Not widely utilised }\end{array}$ \\
\hline 21 & $\begin{array}{l}\text { SUSDRAIN } \\
\text { (CIRIA) }\end{array}$ & $\begin{array}{l}\text { Construction Industry Research } \\
\text { and Information Association }\end{array}$ & $\begin{array}{l}\text { A sustainable drainage-focused network run by an independent not-for-profit research, information } \\
\text { and training organisation supporting research and advocacy of RWH }\end{array}$ \\
\hline 22 & AnglianW & Anglian Water & $\begin{array}{l}\text { WSP with experience in RWH systems, though in a negative sense as some properties in its area were } \\
\text { misconnected, leading it to be a step ahead in monitoring RWH installations in its area }\end{array}$ \\
\hline 23 & Defra & $\begin{array}{l}\text { Dept. for environment, food and } \\
\text { rural affairs }\end{array}$ & $\begin{array}{l}\text { Ministerial department supported by } 35 \text { agencies and public bodies, including the water sector } \\
\text { regulators (DWI, EA and Ofwat). Funds the WTL (No. 26) }\end{array}$ \\
\hline 24 & RWH & Rainwater Harvesting & $\begin{array}{l}\text { Well-established RWH supplier and installer, used to internally innovating in response to the market. } \\
\text { Just launched a new dual-purpose RWH system ('RainActiv') }\end{array}$ \\
\hline 25 & Watef & Water Efficiency Network & $\begin{array}{l}\text { A small, friendly network of professionals with an interest in water efficiency, including } \mathrm{RWH} \text {, has } \\
\text { technical committees and runs an annual conference }\end{array}$ \\
\hline 26 & WTL & Water Technology List & $\begin{array}{l}\text { Defra-funded and managed by Ricardo-AEA, this list contains RWH products by a range of approved } \\
\text { suppliers. Enables businesses to reclaim tax against any purchases of listed kit }\end{array}$ \\
\hline 27 & $\mathrm{ACO}$ & ACO Water Management & $\begin{array}{l}\text { A global company sourcing and delivering sustainable surface water management systems. Internal } \\
\text { innovator of a range of RWH-focused products in response to regulatory and other drivers }\end{array}$ \\
\hline 28 & NottTrent & Nottingham Trent University & Represented by an academic who has been active in research and teaching on RWH since the 1990s \\
\hline 29 & CovUni & Coventry University & Represented by an academic who has been active in research and teaching on RWH since the 1990s \\
\hline 30 & EA & Environment Agency & $\begin{array}{l}\text { Environmental regulator for the water sector and responsible for producing guidance on RWH. } \\
\text { Criticised for the methodology it used in } 2010 \text { to produce a report on the energy and carbon } \\
\text { implications of RWH }\end{array}$ \\
\hline
\end{tabular}


To bridge this gap and strengthen the analytical framework, features from the previously mentioned Safe and SuRe framework are also utilised [4,41]. The basic definitions of resilience and sustainability, as well as some key terms (threats, systems, impacts, consequences etc.) adopted by the framework were outlined at the end of Section 1. As an emerging framework that is nascent in its application, it is not possible or appropriate to debate or criticise the use of the Safe and SuRe framework within this paper, but as with the MLP, its use requires justification. Firstly, the definitions of resilience and sustainability place emphasis on a service level, thereby specifying and emphasizing the performance of a system (in relation to resilience and sustainability), but not the properties that a system must have in order to achieve that level of performance. As such, the framework is flexible in its identification of the characteristics of a system that might result in resilience and sustainability. This is in contrast to the MLP, which assumes that to be successful, to destabilise the regime or to contribute to sustainability transitions, a niche or TA must exhibit certain characteristics. Whilst the Safe and SuRe framework focuses on performance rather than properties, it may be pertinent in the pilot study to use both aspects in order to highlight where service levels (in relation to RWH infrastructures and organisations) are overlooked or missing and where certain characteristics may be crucial for system (RWH niche) function. Secondly, categories are used within the framework to offer a unique view on different threats, middle states (or failure states, where an effect is observed in a system but its cause is unknown), impacts and consequences that may affect the niche, regime or landscape. These include internal (occurring within a system), external (occurring outside a system), chronic (occurring gradually), acute (rapid and/or unpredicted), functional (affecting operations), structural (affecting properties), tangibility (ease of assessment) and directness (direct or indirect effects). Finally, the framework suggests interventions at the intersects between threats, systems, impacts and consequence, which are mitigation, adaptation, coping and learning, respectively. These interventions indicate that resilience and sustainability are built in different ways at different points in the process from threat to consequence and either reduce negative consequences or increase positive consequences. This has applicability when interrogating how UK RWH infrastructures and organisations interact and the effect those interactions have on niche properties and performance.

By using this MLP/niche management-Safe and SuRe combination, it is anticipated that a deeper analysis will be facilitated and a more comprehensive interrogation of the interactions of the RWH infrastructure innovators and organisations achieved. This analysis is presented in the following section.

\section{Results and Discussion}

This section describes the results of the analysis undertaken by applying the SNA and analytical framework outlined in the previous section. The first section discusses the features of the RWH network, as well as visualising interactions in the form of SNA graphs produced through the application of selected SNA metrics. The second section systematically applies the concepts and definitions of the analytical framework to the RWH network interaction model, enabling a narrative to be built regarding niche management, resilience and sustainability.

\subsection{Rainwater Harvesting and Social Network Interactions}

The generated integrated infrastructure-organisation model representing RWH and social network interactions, is represented visually in Figure 2. The abbreviations used in Figure 2 are summarised in Table 1 along with full actor names and a brief description. Nodes in the network represent both RWH infrastructures (in this case specific RWH innovators) and organisations (both small and large enterprises) and five principal categories of node were identified:

1. RWH infrastructure innovator (green circle) —infrastructure providers who have developed a novel RWH product, process or service; 
2. Research organisation (blue diamond) - universities, institutions or project collaborations that are actively engaged in RWH research and knowledge creation;

3. Network (light blue square)-membership-based organisations relating to RWH that are comprised of other actors, but coordinated by a small management team;

4. Water/consultancy service provider (light blue oval)—large organisations directly or indirectly innovating or implementing in relation to RWH products and services;

5. Decision/policy maker (green triangle)—central government support for RWH.

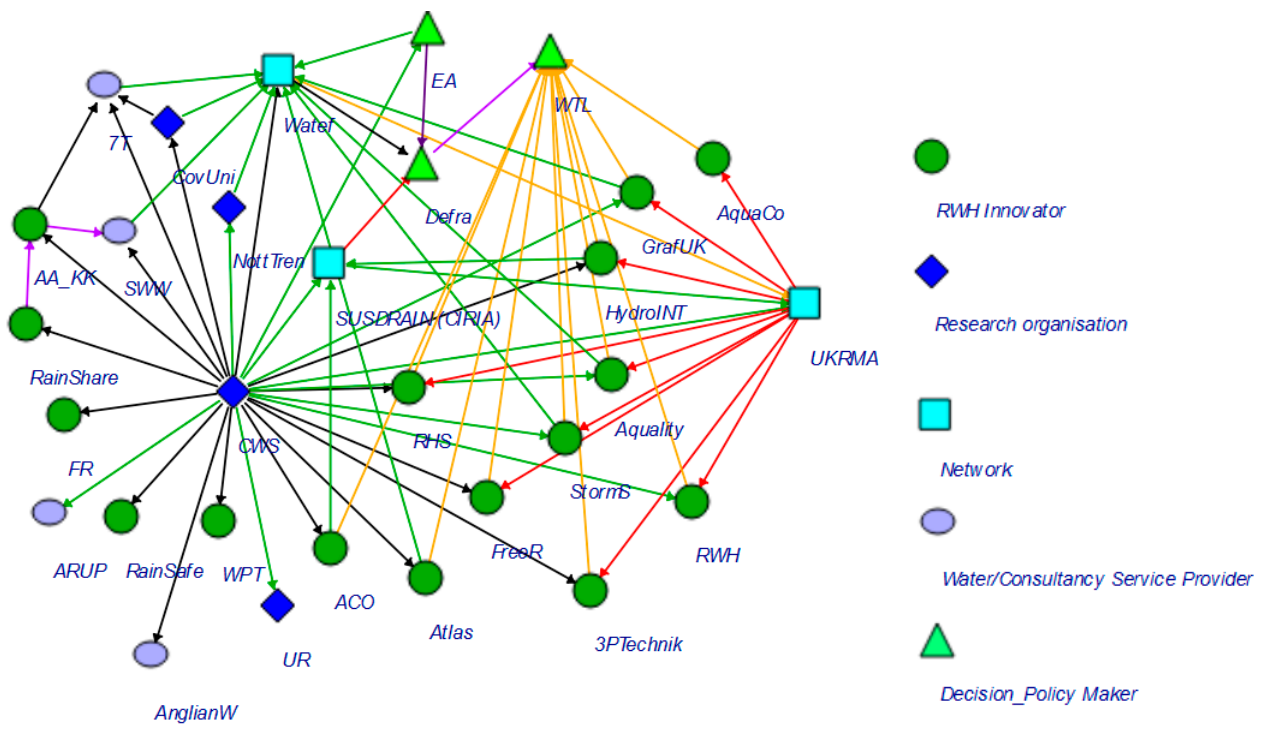

Figure 2. Relationships between infrastructure innovators and other organisations in the UK rainwater harvesting network interaction model. Relationships: Green = knowledge exchange; Black = research; Purple $=$ action; Red $=$ Advocacy $/$ lobbying; Orange $=$ listed by WTL .

Using the metrics available through SNA it is possible to quantitatively examine the RWH network interaction model. Figure 3 illustrates the influence range closeness centrality (IRCC) of the model, which represents the distance from a specific node to another and therefore the extent of its influence [47]. The SNA identified that some RWH infrastructure innovators have limited direct interaction with higher-level organisations and therefore have a weak influence. Instead they interact primarily through persuasive intermediaries such as the CWS and the UK Rainwater Management Association (UKRMA), which due to their diversity of relationships they have wide influence. From Figures 2 and 3 it is also possible to see that the RWH infrastructure innovators who are not traditional operators in the network are generally not connected to the UKRMA, again reducing their influence. To explore this further, the reachability metric was used, which is a metric to quantify the ability to get from one edge (in this case, relationship) to another [59]. By examining the reachability matrix generated by SocNetV for the RWH network interaction model (Table 2), it was identified that the CWS is the most reachable organisation (score of 29, ranked first). CWS performs a facilitation, configuring and brokering role across the RWH network, similar to that of the UKRMA, which is on the next level of reachability. Important to note here is the bias introduced through the creation of the social network, which was of course constructed by members of the CWS. The position of CWS as central actor is defendable in that it is an internationally recognised Centre of expertise on RWH, with an extensive range of publications (both academic and industrial) in the field. Brief interrogation of other actor websites did not reveal a comparable level of activity. Arguably it would be of use to verify the connections between the actors and relationships included in the RWH social network and that is the subject of ongoing research. 
Table 2. Reachability matrix for infrastructure innovators and organisations in the rainwater harvesting network interaction model.

\begin{tabular}{|c|c|c|c|c|c|c|c|c|c|c|c|c|c|c|c|c|c|c|c|c|c|c|c|c|c|c|c|c|c|c|c|c|c|}
\hline SNA No. & Name & 1 & 2 & 3 & 4 & 5 & 6 & 7 & 8 & 9 & 10 & 11 & 12 & 13 & 14 & 15 & 16 & 17 & 18 & 19 & 20 & 21 & 22 & 23 & 24 & 25 & 26 & 27 & 28 & 29 & 30 & Score & Rank \\
\hline 1 & CWS & 0 & 1 & 1 & 1 & 1 & 1 & 1 & 1 & 1 & 1 & 1 & 1 & 1 & 1 & 1 & 1 & 1 & 1 & 1 & 1 & 1 & 1 & 1 & 1 & 1 & 1 & 1 & 1 & 1 & 1 & 29 & 1 \\
\hline 2 & UKRMA & 0 & 0 & 0 & 0 & 1 & 0 & 0 & 1 & 0 & 0 & 0 & 0 & 1 & 0 & 1 & 1 & 1 & 1 & 1 & 0 & 1 & 0 & 1 & 1 & 1 & 1 & 0 & 0 & 0 & 0 & 13 & 11 \\
\hline 3 & WPT & 0 & 0 & 0 & 0 & 0 & 0 & 0 & 0 & 0 & 0 & 0 & 0 & 0 & 0 & 0 & 0 & 0 & 0 & 0 & 0 & 0 & 0 & 0 & 0 & 0 & 0 & 0 & 0 & 0 & 0 & 0 & 24 \\
\hline 4 & RainShare & 0 & 1 & 0 & 0 & 1 & 0 & 1 & 1 & 0 & 0 & 1 & 0 & 1 & 1 & 1 & 1 & 1 & 1 & 1 & 0 & 1 & 0 & 1 & 1 & 1 & 1 & 0 & 0 & 0 & 0 & 17 & 2 \\
\hline 5 & 3PTechnik & 0 & 0 & 0 & 0 & 0 & 0 & 0 & 0 & 0 & 0 & 0 & 0 & 0 & 0 & 0 & 0 & 0 & 0 & 0 & 0 & 0 & 0 & 0 & 0 & 0 & 1 & 0 & 0 & 0 & 0 & 1 & 18 \\
\hline 6 & FR & 0 & 0 & 0 & 0 & 0 & 0 & 0 & 0 & 0 & 0 & 0 & 0 & 0 & 0 & 0 & 0 & 0 & 0 & 0 & 0 & 0 & 0 & 0 & 0 & 0 & 0 & 0 & 0 & 0 & 0 & 0 & 25 \\
\hline 7 & AA_KK & 0 & 1 & 0 & 0 & 1 & 0 & 0 & 1 & 0 & 0 & 1 & 0 & 1 & 1 & 1 & 1 & 1 & 1 & 1 & 0 & 1 & 0 & 1 & 1 & 1 & 1 & 0 & 0 & 0 & 0 & 16 & 3 \\
\hline 8 & StormS & 0 & 1 & 0 & 0 & 1 & 0 & 0 & 0 & 0 & 0 & 0 & 0 & 1 & 0 & 1 & 1 & 1 & 1 & 1 & 0 & 1 & 0 & 1 & 1 & 1 & 1 & 0 & 0 & 0 & 0 & 13 & 12 \\
\hline 9 & Atlas & 0 & 1 & 0 & 0 & 1 & 0 & 0 & 1 & 0 & 0 & 0 & 0 & 1 & 0 & 1 & 1 & 1 & 1 & 1 & 0 & 1 & 0 & 1 & 1 & 1 & 1 & 0 & 0 & 0 & 0 & 14 & 5 \\
\hline 10 & RainSafe & 0 & 0 & 0 & 0 & 0 & 0 & 0 & 0 & 0 & 0 & 0 & 0 & 0 & 0 & 0 & 0 & 0 & 0 & 0 & 0 & 0 & 0 & 0 & 0 & 0 & 0 & 0 & 0 & 0 & 0 & 0 & 26 \\
\hline 11 & $7 \mathrm{~T}$ & 0 & 1 & 0 & 0 & 1 & 0 & 0 & 1 & 0 & 0 & 0 & 0 & 1 & 0 & 1 & 1 & 1 & 1 & 1 & 0 & 1 & 0 & 1 & 1 & 1 & 1 & 0 & 0 & 0 & 0 & 14 & 6 \\
\hline 12 & UR & 0 & 0 & 0 & 0 & 0 & 0 & 0 & 0 & 0 & 0 & 0 & 0 & 0 & 0 & 0 & 0 & 0 & 0 & 0 & 0 & 0 & 0 & 0 & 0 & 0 & 0 & 0 & 0 & 0 & 0 & 0 & 27 \\
\hline 13 & FreeR & 0 & 0 & 0 & 0 & 0 & 0 & 0 & 0 & 0 & 0 & 0 & 0 & 0 & 0 & 0 & 0 & 0 & 0 & 0 & 0 & 0 & 0 & 0 & 0 & 0 & 1 & 0 & 0 & 0 & 0 & 1 & 19 \\
\hline 14 & SWW & 0 & 1 & 0 & 0 & 1 & 0 & 0 & 1 & 0 & 0 & 0 & 0 & 1 & 0 & 1 & 1 & 1 & 1 & 1 & 0 & 1 & 0 & 1 & 1 & 1 & 1 & 0 & 0 & 0 & 0 & 14 & 7 \\
\hline 15 & RHS & 0 & 0 & 0 & 0 & 0 & 0 & 0 & 0 & 0 & 0 & 0 & 0 & 0 & 0 & 0 & 0 & 0 & 0 & 0 & 0 & 0 & 0 & 0 & 0 & 0 & 1 & 0 & 0 & 0 & 0 & 1 & 20 \\
\hline 16 & Aquality & 0 & 1 & 0 & 0 & 1 & 0 & 0 & 1 & 0 & 0 & 0 & 0 & 1 & 0 & 1 & 0 & 1 & 1 & 1 & 0 & 1 & 0 & 1 & 1 & 1 & 1 & 0 & 0 & 0 & 0 & 13 & 13 \\
\hline 17 & GrafUK & 0 & 1 & 0 & 0 & 1 & 0 & 0 & 1 & 0 & 0 & 0 & 0 & 1 & 0 & 1 & 1 & 0 & 1 & 1 & 0 & 1 & 0 & 1 & 1 & 1 & 1 & 0 & 0 & 0 & 0 & 13 & 14 \\
\hline 18 & AquaCo & 0 & 0 & 0 & 0 & 0 & 0 & 0 & 0 & 0 & 0 & 0 & 0 & 0 & 0 & 0 & 0 & 0 & 0 & 0 & 0 & 0 & 0 & 0 & 0 & 0 & 1 & 0 & 0 & 0 & 0 & 1 & 21 \\
\hline 19 & HydroINT & 0 & 1 & 0 & 0 & 1 & 0 & 0 & 1 & 0 & 0 & 0 & 0 & 1 & 0 & 1 & 1 & 1 & 1 & 0 & 0 & 1 & 0 & 1 & 1 & 1 & 1 & 0 & 0 & 0 & 0 & 13 & 15 \\
\hline 20 & ARUP & 0 & 0 & 0 & 0 & 0 & 0 & 0 & 0 & 0 & 0 & 0 & 0 & 0 & 0 & 0 & 0 & 0 & 0 & 0 & 0 & 0 & 0 & 0 & 0 & 0 & 0 & 0 & 0 & 0 & 0 & 0 & 28 \\
\hline 21 & SUSDRAIN & 0 & 1 & 0 & 0 & 1 & 0 & 0 & 1 & 0 & 0 & 0 & 0 & 1 & 0 & 1 & 1 & 1 & 1 & 1 & 0 & 0 & 0 & 1 & 1 & 1 & 1 & 0 & 0 & 0 & 0 & 13 & 16 \\
\hline 22 & AnglianW & 0 & 0 & 0 & 0 & 0 & 0 & 0 & 0 & 0 & 0 & 0 & 0 & 0 & 0 & 0 & 0 & 0 & 0 & 0 & 0 & 0 & 0 & 0 & 0 & 0 & 0 & 0 & 0 & 0 & 0 & 0 & 29 \\
\hline 23 & Defra & 0 & 0 & 0 & 0 & 0 & 0 & 0 & 0 & 0 & 0 & 0 & 0 & 0 & 0 & 0 & 0 & 0 & 0 & 0 & 0 & 0 & 0 & 0 & 0 & 0 & 1 & 0 & 0 & 0 & 0 & 1 & 22 \\
\hline 24 & RWH & 0 & 0 & 0 & 0 & 0 & 0 & 0 & 0 & 0 & 0 & 0 & 0 & 0 & 0 & 0 & 0 & 0 & 0 & 0 & 0 & 0 & 0 & 0 & 0 & 0 & 1 & 0 & 0 & 0 & 0 & 1 & 23 \\
\hline 25 & Watef & 0 & 1 & 0 & 0 & 1 & 0 & 0 & 1 & 0 & 0 & 0 & 0 & 1 & 0 & 1 & 1 & 1 & 1 & 1 & 0 & 1 & 0 & 1 & 1 & 0 & 1 & 0 & 0 & 0 & 0 & 13 & 17 \\
\hline 26 & WTL & 0 & 0 & 0 & 0 & 0 & 0 & 0 & 0 & 0 & 0 & 0 & 0 & 0 & 0 & 0 & 0 & 0 & 0 & 0 & 0 & 0 & 0 & 0 & 0 & 0 & 0 & 0 & 0 & 0 & 0 & 0 & 30 \\
\hline 27 & $\mathrm{ACO}$ & 0 & 1 & 0 & 0 & 1 & 0 & 0 & 1 & 0 & 0 & 0 & 0 & 1 & 0 & 1 & 1 & 1 & 1 & 1 & 0 & 1 & 0 & 1 & 1 & 1 & 1 & 0 & 0 & 0 & 0 & 14 & 8 \\
\hline 28 & NottTrent & 0 & 1 & 0 & 0 & 1 & 0 & 0 & 1 & 0 & 0 & 0 & 0 & 1 & 0 & 1 & 1 & 1 & 1 & 1 & 0 & 1 & 0 & 1 & 1 & 1 & 1 & 0 & 0 & 0 & 0 & 14 & 9 \\
\hline 29 & CovUni & 0 & 1 & 0 & 0 & 1 & 0 & 0 & 1 & 0 & 0 & 1 & 0 & 1 & 0 & 1 & 1 & 1 & 1 & 1 & 0 & 1 & 0 & 1 & 1 & 1 & 1 & 0 & 0 & 0 & 0 & 15 & 4 \\
\hline 30 & EA & 0 & 1 & 0 & 0 & 1 & 0 & 0 & 1 & 0 & 0 & 0 & 0 & 1 & 0 & 1 & 1 & 1 & 1 & 1 & 0 & 1 & 0 & 1 & 1 & 1 & 1 & 0 & 0 & 0 & 0 & 14 & 10 \\
\hline
\end{tabular}




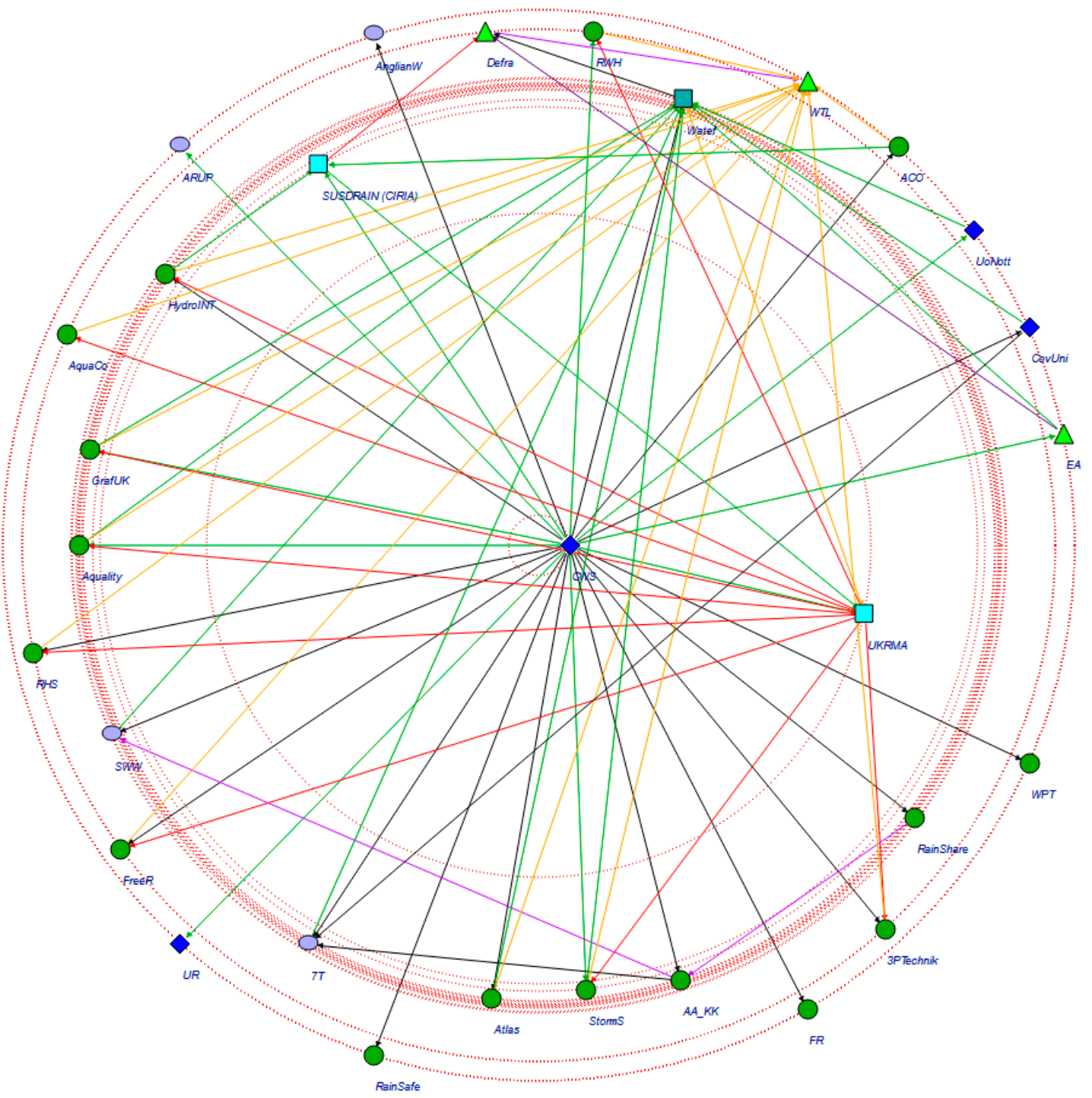

Figure 3. Influence range closeness centrality (IRCC) hierarchy for the rainwater harvesting network interaction model. Relationships: Green = knowledge exchange; Black = research; Purple = action; Red = Advocacy / lobbying; Orange = listed by WTL.

Bearing this bias in mind, it was identified that two RWH infrastructure innovators showed higher reachability scores (RainShare and AquaAnalytics). The analysis suggests that these actors have consistently succeeded in connecting with both commercial and research circles, embedding their collaborative research outcomes within their offer to the RWH market. They could be perceived as the most resilient innovators, as they respond to threats such as changes in regulation and market demand, as well as failures in centralised support. That is, the products and services they produce and refine are based on research and market assessments (via networks) and meet the need of a growing market. As such, they do not depend on any formal structure of support, such as a subsidy or feed-in tariff equivalent scheme in order to enhance their attractiveness or generate demand. Table 2 also shows that the RWH network is disconnected as there are five organisations with only one known interaction. Finally, the clusterability of the network is zero, indicating a low number of 'cliques', which results in a large number of members participating in the same knowledge networks. This could be problematic for the resilience of the network, its influence on the regime and landscape and ultimately water sector sustainability transitions. This will be explored further in the following section. 
An organisational layer not represented in the hierarchy visualised in Figure 3, is that of end-users; those who have RWH systems within their homes, schools, supermarket and pub chains, other building/property types and so on. Recent research by Delaney and Fam [60] using practice theory principles, has highlighted (in an Australian context) the role of meanings and conceptualisations of rainwater for RWH end-users. Historical, cultural and emotional meanings of rainwater shape its use in everyday practices-it means different things to different people and correspondingly consumption of rainwater occurs at different volumetric scales [61]. Consequently, it seems there would be added value from a coordinated effort to include end-users more explicitly in the RWH network interactions. In this way RWH infrastructure innovators would be connected to communities representing their markets, which could also facilitate better engagement at higher organisational levels of the network. With regard to decision makers who should perhaps be present in the model, several higher tier government departments are missing as whilst they have programmes linked with RWH in some way, they do not have schemes specifically addressing RWH.

\subsection{Implications of Rainwater Harvesting Network Interactions for Niche Management, Resilience and Sustainability}

The concepts of niche management, resilience and sustainability, as defined within the context of this paper, were summarised in the Introduction section. As mentioned in the Methodology section, it is important to recontextualise the quantitative SNA presented in the Results section within a more qualitative narrative, particularly as niche management, resilience and sustainability agendas are of interest in this pilot study. Consequently, this section applies the analytical framework described in the Methodology section in order to fulfil the aim of the paper, which is to examine how resilience and sustainability feature within niche processes. The information, knowledge and experience collated through the modified participatory SNA phase of the pilot study is interpreted in narrative form in this section and cross-referenced to the analytical framework.

\subsubsection{Rainwater Harvesting and Niche Management}

The strategic niche management (SNM) concepts of expectations, learning and networks [62] are embedded within the RWH network interaction model and are summarised in Table 3 and briefly discussed in turn. For example, in the case of expectations, neither those of the RWH infrastructure innovators or other organisations are clearly articulated or explicitly defined and documented by any organisation or RWH infrastructure innovator. Theory suggests that expectations need to become embedded promises in order to reduce risks, legitimate the niche, increase credibility, build consensus, attract resources and increase the functional value of the niche. The formulation of an 'expectation statement', perhaps collaboratively derived with input from the regime and landscape (including regulators/decision makers and end users), may be required by the niche actors, covering targets for the RWH niche to work towards. This could contribute to addressing drivers/challenges other than water supply, such as reduced energy usage and storm-water to sewer reduction, as identified in Melville-Shreeve et al. [54]. The lack of converged expectations indicates that the regime may not be committed to the RWH infrastructure innovators because it does not know what to expect in the future and is reluctant to set performance targets (for example, some RWH infrastructure innovators campaign for subsidies, others reject the idea; some organisations emphasise proof of RWH system performance, but set no criteria for comparison). 
Table 3. Summary of how niche creation and management features are represented in the rainwater harvesting niche in the UK.

\begin{tabular}{|c|c|}
\hline Niche Feature & Application to the RWH Niche \\
\hline \multicolumn{2}{|l|}{ Niche Creation } \\
\hline Selection of candidate technology & A range of organisations have selected and supported the niche including CWS, UKRMA, water companies, consultants \\
\hline Selection of setting for local project/s & $\begin{array}{l}\text { Many local projects over a } 15 \text { year period-settings often of convenience rather than to demonstrate how advantages } \\
\text { outweigh disadvantages }\end{array}$ \\
\hline Define local project & $\begin{array}{l}\text { Local goal—save water, attenuate runoff, provide a system/service to customer (business goal—sell products, embed the } \\
\text { niche in the regime) }\end{array}$ \\
\hline Scale-up local projects & $\begin{array}{l}\text { Conventional RWH systems have been scaled up by RWH Infrastructure Innovators. Limited accessible performance data } \\
\text { limits visibility of this. }\end{array}$ \\
\hline $\begin{array}{l}\text { Dismantle protection mechanisms to } \\
\text { promote independence }\end{array}$ & No formal protection mechanisms exist to dismantle (with the exception of the limited Enhanced Capital Allowance) \\
\hline $\begin{array}{l}\text { Availability of sheltered spaces } \\
\text { for incubation }\end{array}$ & No spaces exist for RWH \\
\hline $\begin{array}{l}\text { Possibility for continuous evaluation } \\
\text { and incremental improvement }\end{array}$ & $\begin{array}{l}\text { Direct and indirect drivers to continue incremental improvement e.g., low energy/carbon systems, dual-functionality, } \\
\text { ensure that products are suitable for market, to which RWH Infrastructure Innovators have responded }\end{array}$ \\
\hline $\begin{array}{l}\text { Exhibition of possibilities for capturing } \\
\text { increasing returns or } \\
\text { learning economies }\end{array}$ & $\begin{array}{l}\text { RWH Infrastructure Innovators are opening doors for systems with higher rates of return than conventional RWH systems. } \\
\text { Potential for learning economies, as RWH services are an under researched area, but due to the low price of potable mains } \\
\text { water, returns for RWH are limited unless drivers (crises) are present }\end{array}$ \\
\hline $\begin{array}{l}\text { Openness to development in } \\
\text { different directions }\end{array}$ & $\begin{array}{l}\text { Potential for } 72 \text { different and technically feasible RWH system configurations has recently been identified by CWS research. } \\
\text { Non-RWH Infrastructure Innovators now beginning to realise there are options other than conventional systems, but } \\
\text { require evidence that these perform as intended }\end{array}$ \\
\hline $\begin{array}{l}\text { Favoured in certain applications } \\
\text { so that advantages } \\
\text { outweigh disadvantages }\end{array}$ & $\begin{array}{l}\text { RWH is not a 'one size fits all' innovation and different types are required for different contexts. Work is ongoing with } \\
\text { RWH Infrastructure Innovators to determine which types best fit which contexts }\end{array}$ \\
\hline \multicolumn{2}{|l|}{ Strategic Niche Management } \\
\hline Expectations (promises, actions) & $\begin{array}{l}\text { Until the RWH niche can prove what it says (water efficiency, low energy, dual-function) there is no expectation of support. } \\
\text { RWH Infrastructure Innovators are adjusting their visions to circumstances and promising and delivering low energy and } \\
\text { dual-function systems, but require targets to work with }\end{array}$ \\
\hline
\end{tabular}


Table 3. Cont

\begin{tabular}{|c|c|}
\hline Niche Feature & Application to the RWH Niche \\
\hline Learning & $\begin{array}{l}\text { 1. Technical aspects and design specifications-conventional RWH systems have these, they are being developed for } \\
\text { new configurations } \\
\text { 2. Cultural and symbolic meaning-UKRMA undertook a survey, CWS has ongoing research in this area } \\
\text { 3. Market and user preferences-Coventry Uni proposing research in this area } \\
\text { 4. Infrastructure and maintenance works-emphasis on developing low maintenance and energy and } \\
\text { high retrofitability } \\
\text { 5. Industry and production networks-these are now diverse } \\
\text { 6. Regulations and government policy-RWH is encourage but not direct supported } \\
\text { 7. Societal and environmental effects-RWH innovators are responding to need for low energy and } \\
\text { retrofittable systems }\end{array}$ \\
\hline Networks (interactions) & $\begin{array}{l}\text { Most RWH Infrastructure Innovators are linked to a network, research organisation or water service provider, but the } \\
\text { quality of interaction varies and approaches to change agendas and visions of the regime can be pushy and confrontational. } \\
\text { Consequently, RWH niche profile could be seen as being dominated by trade bodies/product sellers-RWH potentially } \\
\text { needs better representation by an independent champion }\end{array}$ \\
\hline \multicolumn{2}{|l|}{ Conceptual Niche Management } \\
\hline Define a concept & $\begin{array}{l}\text { New RWH Infrastructure Innovators are beginning to introduce service innovation/social enterprise concepts } \\
\text { (e.g., AquaAnalytics and RainShare), but regime has yet to stimulate such ideas }\end{array}$ \\
\hline Explore its social embedding & New RWH Infrastructure Innovators and networks (Watef) are beginning to explore this area \\
\hline Start talks with 'new' actors & A range of actors are holding discussions on the utility of RWH for reliable, resilient and sustainable water systems \\
\hline Set up experiments & Very few examples other than those already given above \\
\hline Evaluation and learning & Yet to be actioned \\
\hline \multicolumn{2}{|l|}{ Social Niche Management } \\
\hline $\begin{array}{l}\text { Values-niche-regime differences and } \\
\text { interactions expressed }\end{array}$ & $\begin{array}{l}\text { Niche needs to focus resources on better expressing how it meets the regime's needs and regime needs to provide } \\
\text { targets/criteria to meet }\end{array}$ \\
\hline Existence in the social economy & $\begin{array}{l}\text { Limited RWH Infrastructure Innovator action in the social economy, with most focusing on sales with peripheral or } \\
\text { coincidental social goals }\end{array}$ \\
\hline Pluralistic resource base & $\begin{array}{l}\text { Some RWH innovators (WPT, Flushrain) are creative in obtaining external funding where possible due to a lack of } \\
\text { dedicated subsidies/external funds, thus the niche is free to identify schemes of relevance }\end{array}$ \\
\hline $\begin{array}{l}\text { Communities of Interest (CoI) or } \\
\text { Location }(\mathrm{CoL})\end{array}$ & RWH CoI sit within CoL. CoI orient around RWH systems themselves, CoL orient around using RWH to achieve a local goal \\
\hline $\begin{array}{l}\text { Conventional and alternative } \\
\text { innovations are permitted to combine }\end{array}$ & $\begin{array}{l}\text { Drive towards 'urban demonstrator' type projects where numerous interventions are implemented in physically or } \\
\text { virtually proximal locations and any number of technical, service or social schemes are permissible for use in combination } \\
\text { if relevant buy-in can be achieved with other stakeholders }\end{array}$ \\
\hline
\end{tabular}


Further evidence of conflicting expectations and questionable commitment to the RWH niche is visible through the lack of available protection mechanisms (none exist, with the exception of the Enhanced Capital Allowance, through the Water Technology List, which is a tax rebate scheme and only available to businesses [63]. The UK RWH niche has largely been operating independently since its formation, though various campaigns to generate government support for the provision of protected spaces have been (unsuccessfully) run. In contrast to the renewable energy niche, the government in England and Wales has not seen it as its place to directly intervene in the direction of innovation for the water sector. Consequently, whilst it encourages the promotion of options such as RWH, including their technical innovation, it provides no formal support and expectations are that the water sector will take appropriate actions to innovate for resilience and sustainability, but with the customer and low water bills as a priority. This reinforces the assertion by Chavarria and Pedroso [64] that system performance in relation to expectations underpins the commitment of organisations, with such commitment resulting from future expectations related to the niche and regime. As such, agency (capacity to act independently and to make free choices) directs commitment to an existing or new regime. In the RWH context, the misaligned expectations results in a lack of agency on either side, leading to a lack of useful guidance from the regime and consequently a stymied influence by RWH infrastructure innovators. Whilst expectations are unconverged and poorly articulated, it is important to note that the interactions that have occurred have resulted in a highly functioning-perhaps even resilient-network to date. As it links to resilience, this aspect is explored further in the following section.

In relation to learning, as a result of the development of coalitions and network building, coordinated learning does take place between RWH infrastructure innovators and organisations. Referring to Table 3, it was possible to identify a point of relevance for each of the seven learning processes outlined by Schot and Geels [35]. Niche management literature suggests that learning processes have greater benefit for niche development if they are reflexive, translatory and enable strategizing (second order learning), as well as facilitating niche-related technological effectiveness and accumulation of data and facts (first order learning). It would appear that whilst a number of RWH infrastructure innovators and research organisations have moved beyond the collection of data and facts, regulators and decision/policy makers have not. This mis-alignment between the high-level organisations and the RWH infrastructure innovators needs to be overcome before forward steps can be taken and greater collective participation is required and policy makers would benefit from consideration of these perspectives. Connecting learning and networks, the options for niche-regime interactions were presented by Mourik and Raven [62] as:

A. If a network primarily comprises traditional organisations practicing first order learning, an innovation will either perish or remain in the niche;

B. If the network primarily comprises traditional organisations practicing second order learning, an innovation will remain in the niche or become an add-on technology to the existing regime;

C. If the network primarily comprises traditional outside organisations and users only practicing first order learning, an innovation is likely to remain an add-on technology to the existing regime or a market niche;

D. If the network primarily comprises traditional outside organisations and users practicing second order learning, an innovation will become an add-on technology to the existing regime or contribute to system change and become an element in a new regime.

In the final type of network, bottom-up partnerships engage organisations to alter the system's structure and agency, which is a precondition for transformation. From the analysis of the RWH network interaction model and assigning organisation and learner types to organisations (Table 4), based on the autobiographical sketch, it is possible to estimate the network type in relation to the interactions (A-D) - it would seem the RWH niche-network is approaching a type D. However, whilst there is a diversity of all organisation types, there is a dominance of traditional organisations 
demonstrating second order learning, which rather than a type D, could result in a type B, where the niche becomes an add on to the existing regime and may end up drifting within the mainstream.

Table 4. Different organisation and learner types in the rainwater harvesting network interaction model.

\begin{tabular}{cccc}
\hline Organisation Type & Number of Organisations & Learner Type & Number of Organisations \\
\hline Traditional & 11 & First order & 3 \\
Non-traditional & 8 & Second order & 10 \\
User & 5 & Both & 17 \\
Outsider & 12 & & \\
\hline
\end{tabular}

As summarised in Table 3, conceptual niche management (CNM) and social niche management (SoNM) features also operate within the RWH network interaction model. CNM focuses on the embedding of guiding principles used to fulfil societal needs to purposively steer more socially-driven innovations into the mainstream [65]. It orientates around visions (defining a concept, rather than a technology as in SNM), social embedding, engaging with new organisations, experimentation, evaluation and learning. Hegger et al. [66] demonstrated these processes in a study of innovative sanitation. Further to this, Quitzau et al. [67] support these processes in their research on 'niche planning', highlighting the value of transformative perspectives from the spatial planning arena. Such perspectives may not be about supporting technological innovation per se, but rather about providing a supportive framework for the broader application of old or new concepts. CNM recognises the role of a range of organisations, including outsiders (government, industry, non-governmental organisations (NGOs), community and voluntary organisations (CVOs), citizen/community groups, research institutes and so on), in formulating, developing and trialling concepts for sustainability.

Examining the RWH network interaction model represented in Figure 2 and Table 1, it is highlighted that new non-technological concepts are beginning to emerge, such as RainShare (organisation No. 4). RainShare [68] is underpinned by the vision of sharing runoff and is socially embedded within local communities, including the Transition Town movement, where it is experimenting with demonstration projects that engage with new organisations, unfamiliar to the RWH niche (such as CVOs). SoNM, evolved from CNM through recent studies focused on grassroots activities, including community initiatives and social enterprises, which may have emerging roles in niche formation and management [23,69]. SoNM can be seen where "The identification of the shared and conflicting values between niche and regime is expected to lead to a better understanding of their (in)compatibility, and to a better anticipation of potential future conflicts than considering levels of stability" [69] (p. 9). Social or grassroots niches comprise innovative networks of advocates and parties leading bottom-up solutions (concepts, processes) for sustainable development, which react to local circumstances and the interests and values of communities involved. As such, the innovations are different to market economy-driven technological ones and they exist in the social economy, express different values, access multiple resources and advocate social innovation. Such features present advantages (act as a vehicle for critical reflection, capacity building and symbolism), but also challenges (amount of resources required to source other resources, poor institutional fit, limited powers of influence). This can result in a modernisation mixture where conventional and alternative ideas, practices and systems are permitted to combine [65]. That is, whilst the complexities enable survival they may also hinder regime-level change and adaptation.

For the RWH niche, SoNM processes are still embryonic and the best example is again RainShare, which was established on primarily social values (reconnecting people with water) and the social economy (sharing of runoff). However, it does link to the market economy in that projects still require technical elements (RWH infrastructure) in order to facilitate the actual runoff sharing. RainShare does, however, access multiple resources in the form of materials, time, money (a range of non-traditional funders) and entrepreneurial support. As an initiative embedded in social innovation, it is also dependent on buy-in from the communities with which it would like to engage and therefore it has to be 
reflexive, adept at building non-traditional capacities in relation to water use within communities and being mindful of the symbolism of water and water using practices within those same communities.

The application of the niche management part of the analytical framework has highlighted occasions when the RWH network interaction model and RWH niche demonstrated elements that are aligned to the concepts of the Safe and SuRe parts of the analytical framework. These are discussed more fully in the following section.

\subsubsection{Rainwater Harvesting, Resilience and Sustainability}

In discussing niche management in relation to the RWH network interaction model, it has emerged that there are phenomena perhaps unaccounted for in SNM, CNM and SoNM approaches. Using the previously discussed features of the Safe and SuRe framework to identify and elucidate these phenomena resulted in the production of Table 5. The 'system' and 'level of service' mentioned in Table 5 denote, respectively, the RWH infrastructure innovators and their ability to perform at a level that is acceptable to both the regime and market (end-users in the landscape). From Table 5, it becomes apparent that features not identified in current niche management include safety, sustainability and resilience and attributes related to these concepts have been defined.

For example, it was ascertained that whilst the expectations of the RWH network are unconverged and poorly articulated, the interactions that exist within the network have still resulted in a highly functioning network with the ability to meet the needs (levels of service) required by both the regime and end-users. This aligns to the Safe and SuRe concept of resilience, demonstrating that the RWH network shows an element of resilience. Without targets or criteria to fully define the magnitude and duration of meeting those levels of service, however, the network may not be able to fulfil the Safe and SuRe definition of resilience.

A further example recognised in the previous section, is that the RWH niche is beginning to adopt features of SoNM. In the terminology of the Safe and SuRe project, the niche is starting to develop enterprises from the 'middle-out' that demonstrates RWH as an intervention that facilitates mitigation, adaptation, coping and learning. Despite this, the regime has yet to stimulate the idea of social or service innovation in relation to the RWH niche (or in general) and new business models are not yet being seriously considered [70]. This may also therefore hinder the network and niches' ability to develop resilience and to contribute to a sustainability transition in the water sector. However, the niche is able to maintain sales and market share by responding to regime aims with product and service configurations that reduce energy use/carbon emissions/potable water use, have a competitive cost-benefit and are socially acceptable. Therefore the niche does contribute to sustainability within the Safe and SuRe definition.

In addition, the RWH niche has undertaken a self-directed form of governance, which highlights the dynamics of a diversity of interacting RWH infrastructure innovators and organisations. Threats (to use Safe and SuRe terminology) the RWH niche has experienced include regime pressures (policy aims and a focus on conventional large-scale infrastructure, even though it may be unconventional in its water source (e.g., sewer mining or indirect potable reuse. This has resulted in a lack of protected spaces, which reduces its ability to demonstrate advantages over centralised infrastructure.

Furthermore, the identification of a range of learning type combinations demonstrates fluidity, dynamism and reflexivity, which aligns with the Safe and SuRe concepts of adapting, coping, learning and recovery. In the case of the RWH niche, this results in multiple actors, as well as intermediaries, influencing internal niche process and trajectories to meet regime aims-though some RWH infrastructure innovators may be more successful at this than others. 
Table 5. Safe, sustainable and resilient framework concepts and definitions, evidence of their fit to the rainwater harvesting network interaction model and niche and their potential niche management feature.

\begin{tabular}{|c|c|c|c|}
\hline Concept & Definition & Evidence & Feature \\
\hline Safe & $\begin{array}{l}\text { Ability to meet public health (or equivalent) } \\
\text { concerns of the existing regime }\end{array}$ & $\begin{array}{l}\text { Public acceptance for using non-potable water for end uses such as } \\
\text { flushing toilets is growing }\end{array}$ & Safe \\
\hline Sustainable & $\begin{array}{l}\text { The degree to which the system maintains levels } \\
\text { of service in the long-term whilst maximising } \\
\text { social, economic and environmental goals }\end{array}$ & $\begin{array}{l}\text { Maintaining sales and market share by responding to regime aims } \\
\text { with product and service configurations that reduce energy } \\
\text { use/carbon emissions / potable water use, have a competitive } \\
\text { cost-benefit and are socially acceptable }\end{array}$ & Sustainable \\
\hline Resilience & $\begin{array}{l}\text { The degree to which the system minimises level of } \\
\text { service failure magnitude and duration over its } \\
\text { design life when subject to exceptional } \\
\text { conditions (extremes) }\end{array}$ & $\begin{array}{l}\text { In response to the lack of dedicated protection mechanisms and } \\
\text { imposition of threats (see row below), the RWH niche innovates } \\
\text { quickly to maintain its ability to respond to emerging markets. } \\
\text { Frequency is represented by the number of regime events to which the } \\
\text { niche must respond, magnitude is whether the innovation response } \\
\text { needs to be incremental or radical and duration is the time to release of } \\
\text { new product/service configurations after regime events are imposed }\end{array}$ & Resilient \\
\hline Threat & $\begin{array}{l}\text { Any internal or external actual and/or likely event } \\
\text { with the potential to reduce the degree to which } \\
\text { the system delivers a defined level of service }\end{array}$ & $\begin{array}{l}\text { Threats the RWH niche has experienced include regime pressures } \\
\text { (policy aims), which temporarily reduced its ability to demonstrate } \\
\text { advantages over centralised infrastructure }\end{array}$ & $\begin{array}{l}\text { No protected spaces; Regime aims } \\
\text { (low carbon (environmental), dual } \\
\text { function/cost-benefit (economic), } \\
\text { retrofittable (social)) }\end{array}$ \\
\hline Impact & $\begin{array}{l}\text { The degree of non-compliance with the defined } \\
\text { level of service (results from a threat) }\end{array}$ & $\begin{array}{l}\text { The proportion of product/services that do not meet regime aims or } \\
\text { market needs }\end{array}$ & Unconverged expectations \\
\hline Consequence & $\begin{array}{l}\text { Any outcomes and effects of the impacts } \\
\text { (i.e., non-compliance with a level of service) on } \\
\text { each pillar of sustainability }\end{array}$ & Inability to respond to sustainability-related regime aims & Unconverged expectations \\
\hline $\begin{array}{l}\text { Intervention: mitigate, } \\
\text { adapt, cope, learn }\end{array}$ & $\begin{array}{l}\text { Reduce the threat; increase reliability and } \\
\text { resilience; reduce the frequency, magnitude or } \\
\text { duration of impact; embed experience in new } \\
\text { knowledge and best practice }\end{array}$ & $\begin{array}{l}\text { Use of intermediaries to understand the policy aims/influence the } \\
\text { regime; Innovate products, services and business models to fit regime } \\
\text { aims (but in this case they do not prove they perform); Ensure } \\
\text { innovations meet regime aims; Learning should be used to } \\
\text { demonstrate attainment of regime-imposed aims and better represent } \\
\text { end-users }\end{array}$ & $\begin{array}{l}\text { Intermediaries influencing the } \\
\text { regime; Fluidity, dynamism and } \\
\text { reflexivity in learning type } \\
\text { combinations }\end{array}$ \\
\hline Recover & $\begin{array}{l}\text { Regain the ability to deliver and comply with a } \\
\text { defined level of service }\end{array}$ & A range of RWH innovators meet the needs of the regime and markets & $\begin{array}{l}\text { Multiple actors influence internal } \\
\text { niche process and trajectories to } \\
\text { meet regime aims }\end{array}$ \\
\hline
\end{tabular}


In summary, as Table 5 highlights, the application of the Safe and SuRe part of the analytical framework has led to the recognition that there may be features operating in the RWH niche that are not represented in niche management literature to date. The seven additional niche governance features identified through the comprehensive interrogation of the RWH network interaction model are:

1. Diverse innovation-technical, social and service innovations with a variety of business models;

2. Responsivity-to regime-level sustainability aims;

3. No protection - no protected spaces and the imposition of threats (drivers) to foster resilience;

4. Unconverged expectations-a functional network that does not necessarily have converged expectations;

5. Primary influencers-intermediaries who are able to persuasively influence and destabilise the existing regime;

6. Polycentric or adaptive governance-where organisations influence internal infrastructure trajectories (though not necessarily with equal weighting) and are inclusive of end-users;

7. Multiple learning-types-fluidity, dynamism and reflexivity in learning type combinations across the actor network.

The analysis presented in Table 5 does not imply that the RWH niche has achieved all of the features to a lesser or greater extent. It merely suggests that these are present within the RWH network interaction model, which is highly functioning despite a number of features inconsistent with SNM, CNM and SoNM. Indeed, the performance of the RWH niche-network in relation to some of the features could be greatly improved, for example by engaging end-users. Until both RWH infrastructure innovators and other organisations more holistically engage end-users, the niche's impact on the water using practices of the landscape will be minimal.

The analysis presented only relates, currently, to the RWH network interaction model; further research on other AWSS or in other infrastructure sectors would be required to verify the presence and validity of the features (this is beyond the scope of the pilot study presented here). However, the suggested features may at least be a useful contribution to governance of the RWH niche. They provide a starting point for action for enhancing RWH network interactions between RWH infrastructure innovators and other organisations, by highlighting the effect of the weak areas and potentially driving more confident and proactive influencing of organisations. For the organisations, the analysis yields a greater understanding of the implicit and tacit knowledge and assumptions inherent in the RWH niche. In establishing these, it becomes easier for organisations to set agendas, though they still need to be flexible in relation to learning types.

\section{Conclusions}

In order to become more sustainable and resilient, the water system must undergo a transition or paradigm shift, or a radical change must be able to occur within the existing regime. To explore these transitions, shifts and changes and the processes that operate within and upon them, a range of models integrated across different components of the system and at different scales is required. This paper contributes a model that represents the network interactions of rainwater harvesting infrastructure innovators and other organisations in the RWH niche operating in the UK, to identify how resilience and sustainability feature within the niche-network. The RWH network interaction model was constructed using a modified participatory social network analysis (SNA). The SNA was then taken further through the application of a two-part analytical framework based on niche management literature (from the multi-level perspective) and the concepts and definitions of the Safe and SuRe framework.

The SNA identified that some RWH infrastructure innovators have limited direct interaction with higher-level organisations and therefore have a weak influence, instead relying on persuasive intermediaries to influence the regime. Two higher level organisations and two emerging RWH infrastructure innovators were the most reachable actors in the network, highlighting their role as 
resilient innovators that respond to regime and landscape-level threats such as changes in regulation and market demand, as well as failures in centralised support. The clusterability of the network was zero, resulting in a large number of members participating in the same knowledge networks, which could be problematic for the resilience of the network, its influence on the regime and landscape and ultimately water sector sustainability transitions. This was reinforced by the limited presence of decision/policy-makers and end-users in the RWH network interaction model, indicating that policy and decision makers should reconsider their involvement in and contribution to the niche, if the regime and landscape-level journey towards resilient and sustainable water management is to be enhanced. Added value could be gained through a coordinated effort to include end-users and decision-makers more explicitly in the RWH network interactions to facilitate greater inclusion of their perspectives, needs and priorities in future water sector resilience and sustainability. Further research is needed to undertake a full PSNA of the RWH network at a different point in time to explore whether representation of end-users and decision-makers changes or is more subtle than was observed in the present study.

By taking the SNA further, through the application of the two-part analytical framework, additional insights were gained. In the case of niche management, features from niche creation and strategic, conceptual and social niche management were exhibited by the RWH network interaction model. For example, from strategic niche management, learning and networks were well expressed, but expectations of the RWH infrastructure innovators and organisations were actually unconverged (the former focused on meeting drivers set by the latter, but without any criteria or targets with which to work), indicating the regime may not be committed to the RWH infrastructure innovators because it does not know what to expect in the future. Despite this lack of converged expectations, the interactions that have occurred have resulted in a highly functioning network, indicating some aspects of resilience. Features from conceptual and social niche management were also present, though some were not well developed. For example, non-technological concepts such as service innovation and social enterprise are emerging, which highlights that the RWH niche is developing to fit the social as well as market economy and is diversifying its appeal.

In the case of the Safe and SuRe part of the analytical framework, by applying the concepts and definitions of the project it was possible to identify features additional to those in existing niche management literature. This is demonstrated by taking further the previously mentioned example regarding the RWH network being highly functioning despite the unconverged and poorly articulated expectations. The interactions that exist within the network have still resulted in the ability to meet the needs (levels of service) required by both the regime and end-users, though they are not explicity included in the network. This aligns to the Safe and SuRe concept of resilience, demonstrating that the RWH network shows an element of resilience. Without targets or criteria to fully define the magnitude and duration of meeting those levels of service, however, the network may not be able to fulfil the Safe and SuRe definition of resilience.

Through the analysis, seven additional niche governance features were identified including diverse innovation, responsivity, no protection, unconverged expectations, primary influencers, polycentric or adaptive governance and multiple learning-types. These features are at varying stages of emergence and indeed, some could be greatly improved, for example, by engaging end-users. Finally, the analysis presented only relates to the RWH network interaction model; further research on other AWSS or in other infrastructure sectors would be useful to verify and validate observation of the seven features. However, the features provide a useful contribution to governance of the RWH niche, enabling RWH infrastructure innovators and organisations to reflect on how to improve and develop the interactions operating within the niche-network.

Acknowledgments: This work is funded by the UK Engineering and Physical Sciences Research Council (EP/K006924/1) and is supported by the Welsh Government, the Environment Agency, the Consumer Council for Water, the Environmental Sustainability Knowledge Transfer Network, the Water Industry Forum, Severn Trent Water, Northumbrian Water, Arup, Black and Veatch, Hyder and ACO Technologies. Sincere thanks go to Sabina Leonelli who helped to shape the direction of the research and thanks to all of the organisations that are 
featured in the analysis presented in this paper, as well as anonymous reviewers for their support in developing this paper.

Author Contributions: The lead author was responsible for conceptualising and applying the methodology, analysing the results and writing the paper. The co-author provided technical input to ensure the results and discussion were adequately exploited and appropriately described herein.

Conflicts of Interest: The authors are involved with some of the organisations included in the analysis presented. They have reflexively considered the impact of this on the analysis and highlighted this in the paper. The sponsors had no role in the design of the study; in the collection, analyses, or interpretation of data; in the writing of the manuscript, and in the decision to publish the results.

\section{References}

1. Holling, C.S. Engineering resilience versus ecological resilience. In Engineering within Ecological Constraints; Schulze, P., Ed.; National Academy of Engineering: Washington, DC, USA, 1996.

2. De Haan, J.H.; Rotmans, J. Patterns in transitions: Understanding complex chains of change. Technol. Forecast. Soc. Chang. 2011, 78, 90-102. [CrossRef]

3. Eppel, E. Governance of a Complex System: Water; Institute for Governance and Policy Studies Working Paper 14/01; Victoria University of Wellington: Wellington, New Zealand, February 2014. Available online: http://www.igps.victoria.ac.nz/publications/files/db8c23b547b.pdf (accessed on 12 November 2015).

4. Butler, D.; Ward, S.; Sweetapple, C.; Astaraie-Imani, M.; Diao, K.; Fu, G.; Farmani, R. Reliable, resilient and sustainable water management: The Safe \& SuRe approach. Glob. Chall. 2016, 1. [CrossRef]

5. De Haan, F.J.; Ferguson, B.C.; Adamowicz, R.C.; Johnstone, P.; Brown, R.R.; Wong, T.H.F. The needs of society: A new understanding of transitions, sustainability and liveability. Technol. Forecast. Soc. Chang. 2014, 85, 121-132. [CrossRef]

6. Farelly, M.A.; Brown, R.R. Making the implicit, explicit: Time for renegotiating the urban water supply hydrosocial contract? Urban Water J. 2014, 11, 392-404. [CrossRef]

7. Urich, C.; Bach, M.P.; Hellbach, C.; Sitzenfrei, R.; Kleidorfer, M.; McCarthy, D.T.; Deletic, A.; Rauch, W. Dynamics of cities and water infrastructure in the DAnCE4Water model. In Proceedings of the 12nd International Conference on Urban Drainage, Porto Alegre, Brazil, 10-15 September 2011.

8. Makropoulos, C.K.; Natsis, K.; Liu, S.; Mittas, K.; Butler, D. Decision support for sustainable option selection in integrated urban water management. Environ. Model. Softw. 2008, 23, 1448-1460. [CrossRef]

9. Astaraie-Imani, M.; Kapelan, Z.; Fu, G.; Butler, D. Assessing the combined effects of urbanisation and climate change on the river water quality in an integrated urban wastewater system. J. Manag. 2012, 112, 1-9. [CrossRef] [PubMed]

10. Fu, G.; Butler, D. Frequency analysis of river water quality using integrated urban wastewater models. Water Sci. Technol. 2012, 65, 2112-2117. [CrossRef] [PubMed]

11. Farmani, R.; Butler, D.; Hunt, D.V.L.; Memon, F.A.; Abdelmeguid, H.; Ward, S.; Rogers, C.D.F. Scenario-based sustainable water management and urban regeneration. Proc. Inst. Civ. Eng. Eng. Sustain. 2012, 65, 89-98. [CrossRef]

12. Mikovits, C.; Rauch, W.; Kleidorfer, M. Dynamics in urban development, population growth and their influences on urban water infrastructure. Proc. Eng. 2014, 70, 1147-1156. [CrossRef]

13. Casal-Campos, A.; Fu, G.; Butler, D.; Moore, A. An integrated environmental assessment of green and gray infrastructure strategies for robust decision making. Environ. Sci. Technol. 2015, 49, 8307-8314. [CrossRef] [PubMed]

14. Ward, S.; Abdelmeguid, H.; Farmani, R.; Memon, F.A.; Butler, D. Sustainable water management-Modelling acceptability for decision support: A methodology. In Proceedings of the Computing and Control for the Water Industry, Exeter, UK, 5-7 September 2011.

15. Bell, S.J.; Shouler, M.; Tahir, S.; Campos, L. Integrating social and technical factors in decision support for non-potable water reuse networks. In Proceedings of the Asia Pacific Water Recycling Conference, Brisbane, Australia, 1-4 July 2013.

16. De Haan, F.J.; Rogers, B.C.; Frantzeskaki, N.; Brown, R.R. Transitions through a lens of urban water. Environ. Innov. Soc. Trans. 2015, 15, 1-10. [CrossRef]

17. Geels, F. Technological transitions as evolutionary reconfiguration processes: A multi-level perspective and a case study. Res. Policy 2002, 31, 1257-1274. [CrossRef] 
18. Binz, C.; Truffer, B. Technological innovation systems in multi-scalar space. Geogr. Helv. 2011, 66, $254-260$. [CrossRef]

19. Kemp, R.; Schot, J.; Hoogma, R. Regime Shifts to Sustainability through Processes of Niche Formation. The Approach of Strategic Niche Management. Technol. Anal. Strateg. Manag. 1998, 10, 175-195. [CrossRef]

20. Raven, R.P.J.M.; Weterings, R. Transitions and strategic niche management: Towards a competence kit for practitioners. Int. J. Technol. Manag. 2010, 51, 57-74. [CrossRef]

21. Hoolohan, C.; Browne, A. Reframing water efficiency: Determining collective approaches to change water use in the home. Br. J. Environ. Clim. Chang. 2016, 6, 179-191. [CrossRef]

22. Marlow, D.R.; Moglia, M.; Cook, S.; Beale, D.J. Towards sustainable urban water management: A critical reassessment. Water Res. 2013, 47, 7150-7161. [CrossRef] [PubMed]

23. Seyfang, G.; Hielscher, S.; Hargreaves, T.; Martiskainen, M.; Smith, A. A grassroots sustainable energy niche? Reflections on community energy in the UK. Environ. Innov. Soc. Trans. 2014, 13, 21-44. [CrossRef]

24. Domenech, L.; March, H.; Valles, M.; Sauri, D. Learning processes during regime shifts: Empirical evidence from the diffusion of greywater recycling in Spain. Environ. Innov. Soc. Trans. 2015, 15, 26-41. [CrossRef]

25. Lieberherr, E.; Truffer, B. The Impact of Privatization on Sustainability Transitions: A Comparative Analysis of Dynamic Capabilities in Three Water Utilities. Environ. Innov. Soc. Trans. 2015, 15, 101-122. [CrossRef]

26. Lopolito, A.; Morone, P.; Taylor, R. Emerging innovation niches: An agent based model. Res. Policy 2013, 42, 1225-1238. [CrossRef]

27. Van der Brugge, R.; van Raak, R. Facing the adaptive management challenge: Insights from transition management. Ecol. Soc. 2007, 12, 375-386.

28. Van Buuren, A.; Loorbach, D. Policy Innovation in Isolation? Conditions for Policy-Renewal by Transition Arenas and Pilot Projects. Public Manag. Rev. 2009, 11, 375-392. [CrossRef]

29. Loorbach, D. Transition management for sustainable development: A prescriptive, complexity-based governance framework. Governance 2009, 23, 161-183. [CrossRef]

30. Pisano, U. Transition Management as a Governance Tool for Sustainable Development. European Sustainable Development Network Case Study No. 17. 2014. Available online: http:/ /www.sd-network.eu/pdf/case\% 20studies/ESDN\%20Case\%20Study_No\%2017_final.pdf (accessed on 7 June 2016).

31. Geels, F.W. The multi-level perspective on sustainability transitions: Responses to seven criticisms. Environ. Innov. Soc. Trans. 2011, 1, 24-40. [CrossRef]

32. Nastar, M. What drives the urban water regime? An analysis of water governance arrangements in Hyderabad, India. Ecol. Soc. 2014, 19, 190-202. [CrossRef]

33. Wen, B.; van der Zouwen, M.; Horlings, E.; van der Meulen, B.; van Vierssen, W. Transitions in urban water management and patterns of international, interdisciplinary and intersectoral collaboration in urban water science. Environ. Innov. Soc. Trans. 2015, 15, 123-139. [CrossRef]

34. Ter Wal, A.L.J.; Boschma, R.A. Applying social network analysis in economic geography: Framing some key analytic issues. Ann. Reg. Sci. 2009, 43, 739-756. [CrossRef]

35. Schot, J.; Geels, F.W. Strategic niche management and sustainable innovation journeys: Theory, findings, research agenda, and policy. Technol. Anal. Strateg. Manag. 2008, 20, 537-554. [CrossRef]

36. Caniels, M.C.J.; Romijn, H.A. Actor networks in Strategic Niche Management: Insights from social network theory. Futures 2008, 40, 613-629. [CrossRef]

37. Organisation for Economic Co-operation and Development. Water Governance in OECD Countries: A Multi-level Approach. OECD Studies on Water. OECD Publishing. 2011. Available online: http://www.dx. doi.org/10.1787/9789264119284-en (accessed on 7 June 2016).

38. Intergovernmental Panel on Climate Change (IPCC). Climate Change 2001: Impacts, Adaptation, and Vulnerability: Contribution of Working Group II to the Third Assessment Report of the Intergovernmental Panel on Climate Change; Cambridge University Press: Cambridge, UK, 2001.

39. WHO and DFID. Summary and Policy Implications. Vision 2030. The Resilience of Water Supply and Sanitation in the Face of Climate Change. 2009. Available online: http://www.who.int/water_sanitation_ health/publications/vision_2030_summary_policy_implications.pdf (accessed on 5 January 2016).

40. UN-Water. Climate Change Adaptation: The Pivotal Role of Water. 2010. Available online: http://www. unwater.org/downloads/unw_ccpol_web.pdf (accessed on 19 February 2016).

41. Butler, D.; Farmani, R.; Fu, G.; Ward, S.; Diao, K.; Astaraie-Imani, M. A new approach to urban water management: Safe and sure. Proc. Eng. 2014, 89, 347-354. [CrossRef] 
42. Francis, R.; Bekera, B. A metric and frameworks for resilience analysis of engineered and infrastructure systems. Reliab. Eng. Syst. Saf. 2014, 121, 90-103. [CrossRef]

43. Sweetapple, C.; Fu, G.; Butler, D. Multi-objective optimisation of wastewater treatment plant control to reduce greenhouse gas emissions. Water Res. 2015, 55, 52-62. [CrossRef] [PubMed]

44. Mugume, S.N.; Gomez, D.E.; Fu, G.; Farmani, R.; Butler, D. A global analysis approach for investigating structural resilience in urban drainage systems. Water Res. 2015, 81, 15-26. [CrossRef] [PubMed]

45. Segre, S. A Durkheimian Network Theory. J. Class. Sociol. 2004, 4, 215-235. [CrossRef]

46. Prell, C.; Hubacek, K.; Reed, M. Stakeholder analysis and social network analysis in natural resource management. Soc. Nat. Resour. 2009, 22, 501-518. [CrossRef]

47. Edwards, G. Mixed-Methods Approaches to Social Network Analysis; ESRC National Centre for Research Methods Review Paper, ESRC National Centre for Research Methods; University of Manchester: Manchester, UK, 2010.

48. Hubacek, K.; Prell, C.; Reed, M.; Boys, D.; Bonn, A.; Dean, C. Using stakeholder and social network analysis to support participatory processes. Int. J. Biodivers. Sci. Manag. 2006, 2, 249-252. [CrossRef]

49. Schiffer, E.; Hauck, J. Net-Map: Collecting social network data and facilitating network learning through participatory influence network mapping. Field Methods 2010, 22, 231-249. [CrossRef]

50. Springer, A.C.; de Steiguer, J.E. Social network analysis: A tool to improve understanding of collaborative management groups. J. Ext. 2011, 49, 1-8.

51. Fuller, J.; Hermeston, W.; Passey, M.; Fallon, T.; Muyambi, K. Acceptability of participatory social network analysis for problem-solving in Australian Aboriginal health service partnerships. BMC Health Serv. Res. 2012, 12, 1-11. [CrossRef] [PubMed]

52. Beilin, R.; Reichelt, N.T.; King, B.J.; Long, A.; Cam, S. Transition lanscapes and social networks: Examining on-ground community resilience and its implications for policy settings in multiscalar systems. Ecol. Soc. 2013, 18, 247-261.

53. Ward, S.; Barr, S.; Butler, D.; Memon, F.A. Rainwater harvesting in the UK-Socio-technical theory and practice. Technol. Forecast. Soc. Chang. 2012, 79, 1354-1361. [CrossRef]

54. Melville-Shreeve, P.; Ward, S.; Butler, D. Rainwater harvesting typologies for UK houses: A multi criteria anlaysis of system configurations. Water 2016, 8, 129. [CrossRef]

55. Roex, A.; Degryse, J. Introducing the concept of epistemological beliefs into medical education: The hot-air-balloon metaphor. Acad. Med. 2007, 82, 616-620. [CrossRef] [PubMed]

56. Sourceforge. Social Network Visualizer. 2015. Available online: http://www.sourceforge.net/projects/ socnetv / ?source=typ_redirect (accessed on 1 July 2015).

57. Wasserman, S.; Faust, K. Social Network Analysis: Methods and Applications; Cambridge University Press: Cambridge, UK, 1994.

58. Shove, E.; Walker, G. Governing transitions in the sustainability of everyday life. Res. Policy 2010, 39, 471-476. [CrossRef]

59. Markovsky, B. Social network conceptions of group solidarity. In The Problem of Solidarity: Theories and Models; Doreian, P., Fararo, T., Eds.; Routledge: London, UK, 1998; Chapter 11; pp. 343-373.

60. Delaney, C.; Fam, D. The 'meaning' behind household rainwater use: An Australian case study. Technol. Soc. 2015, 42, 179-186. [CrossRef]

61. Strang, V. Gardening the World: Agency, Identity and the Ownership of Water; Berghahn: Oxford, UK, 2013.

62. Mourik, R.; Raven, R. A Practitioner's View on Strategic niche Management. Energy Research Centre of the Netherlands Report, ECN-E-06-039. 2006. Available online: http://www.ecn.nl/docs/library/report/2006/ e06039.pdf (accessed on 21 March 2015).

63. The Water Technology List (WTL). 2015. Available online: http://www.watertechnologylist.co.uk/ (accessed on 17 July 2015).

64. Chevarria, D.; Pedroso, E.A. Agency in socio-tech transition processes. In Proceedings of the 6th International Sustainability Transitions Conference, University of Sussex, Brighton, UK, 25-28 August 2015.

65. Monaghan, A. Conceptual niche management of grassroots innovation for sustainability: The case of body disposal practices in the UK. Technol. Forecast. Soc. Chang. 2009, 76, 1026-1043. [CrossRef]

66. Hegger, D.L.T.; van Vliet, J.; van Vliet, B.J.M. Niche management and its contribution to regime change: The case of innovation in sanitation. Technol. Anal. Strateg. Manag. 2007, 19, 729-746. [CrossRef] 
67. Quitzau, M.-B.; Hoffman, B.; Morten, E. Local niche planning and its strategic implications for implementation of energy-efficient technology. Technol. Forecast. Soc. Chang. 2012, 79, 1049-1058. [CrossRef]

68. Ward, S. Co-watering the grassroots: Combining community participation and social entrepreneurship to share roof runoff. In Proceedings of the Water Efficiency in Buildings Network Conference, Covertry, UK, 7-9 September 2016.

69. Witkamp, M.J.; Raven, R.P.J.M.; Royakkers, L.M.M. Strategic Niche Management of Social Innovation: The Case of Social Entrepreneurship in the Netherlands. Eindhoven Centre for Innovation Studies, Working Paper 10.06. 2011. Available online: http://cms.tm.tue.nl/Ecis/Files/papers/wp2010/wp1006.pdf (accessed on 21 March 2015).

70. Ward, S.; Brown, S.; Burton, A.; Adeyeye, K.; Mannion, N.; Tahir, S.; Gordon, C.; Chen, G. Water Sector Service Innovation: What, where and who? Br. J. Environ. Clim. Chang. 2015, 6, 216-226. [CrossRef]

(C) 2016 by the authors; licensee MDPI, Basel, Switzerland. This article is an open access article distributed under the terms and conditions of the Creative Commons Attribution (CC-BY) license (http://creativecommons.org/licenses/by/4.0/). 